\title{
Cineangiographic and pathological features of the infarct related vessel in successful and unsuccessful thrombolysis
}

\author{
TOMOYA ONODERA, HISAYOSHI FUJIWARA, MASARU TANAKA, \\ DER-JINN WU, MITSUO MATSUDA, GENZOU TAKEMURA, \\ MORIHARU ISHIDA, ATSUSHI KAWAMURA, CHUICHI KAWAI
}

From the Third Division, Department of Internal Medicine, Kyoto University, Kyoto, Japan

SUMMARY The postmortem histology and the results of cineangiography after selective intracoronary thrombolysis in vessels that were recanalised and in those that were not were compared in 21 patients who died within seven days (mean 2 days) of selective intracoronary thrombolysis. There was a persistent intraluminal thrombus in the infarct related coronary artery in five of six segments in which recanalisation was unsuccessful and in one of 15 segments in which recanalisation was successful. Rupture and haemorrhage of the atheromatous plaque were seen in most of the infarct related segments, both in those in which recanalisation was achieved and in those in which it was not. Irregular narrowing and filling defects on the coronary cineangiograms were associated with rupture and haemorrhage of the atheromatous plaque.

These results suggest that failure of coronary thrombolysis to recanalise the infarct related artery does not indicate that the occlusion was not caused by thrombus.

Selective intracoronary thrombolysis and percutaneous transluminal coronary angioplasty are increasingly being performed in patients with acute myocardial infarction. ${ }^{1-7}$ Such treatment often results in recanalisation ${ }^{1-3}$ and reduces mortality. ${ }^{4}$ It may, however, cause haemorrhagic infarction. ${ }^{8}$

It has been reported that the angiographic morphology of a stenosis reflects the histological findings, such as intraluminal thrombus or rupture of an atheromatous plaque..$^{9-12}$ As far as we know, no one has attempted to correlate the angiographic picture and the histological examination in patients treated with selective intracoronary thrombolysis. Also, there are only two reports on the histopathogenesis of successful and unsuccessful recanalisation; both were small studies. ${ }^{13} 14$

We have examined the correlation between the angiographic appearance of lesions and the underlying histopathology after selective intracoronary thrombolysis.

Requests for reprints to Dr Chuichi Kawai, Third Division, Department of Internal Medicine, Faculty of Medicine, Kyoto University, Sakyo-ku, Kyoto 606, Japan.

Accepted for publication 29 November 1989

\section{Patients and methods}

We studied 21 patients ( 14 men and seven women, aged 45-83) who died an hour to seven days (2 (2) days) after selective intracoronary thrombolysis (table 1). Sixteen patients died of cardiogenic shock and five of cardiac rupture. Every patient had selective intracoronary thrombolysis an hour to nine hours after the onset of acute myocardial infarction.

In all of them acute myocardial infarction had been diagnosed on the basis of severe chest pain, serial electrocardiographic changes in the ST-T segment or the appearance of abnormal $Q$ waves or both, and an increase in serum concentrations of creatine kinase. After the vessel that had caused the acute infarction was identified by selective coronary cineangiography, $0.5 \mathrm{mg}$ of glyceryl trinitrate was slowly injected into it. If no change was noted in the angiographic appearance of the vessel, urokinase was continuously and selectively infused at a rate of 24000 units $/ \mathrm{min}$. If the occluded artery was not recanalised after the administration of a large amount of urokinase (720 000-1 680000 units) the attempt was stopped. After selective intracoronary thrombolysis, the patients were treated with aspirin 
Table 1 Summary of patients according to interval from selective intracoronary thrombolysis (SICT) to death

\begin{tabular}{|c|c|c|c|c|c|c|}
\hline $\begin{array}{l}\text { Case } \\
\text { no }\end{array}$ & Age & Sex & $\begin{array}{l}\text { Time from } \\
\text { onset of } \\
A M I \text { to } \\
\text { to SICT }\end{array}$ & $\begin{array}{l}U K \\
(\times 10) \\
I U\end{array}$ & $\begin{array}{l}\text { Time from } \\
\text { SICT to } \\
\text { death }\end{array}$ & $\begin{array}{l}\text { Cause } \\
\text { of } \\
\text { death }\end{array}$ \\
\hline $\begin{array}{c}1 \\
2 \\
3 \\
4 \\
5 \\
6 \\
7 \\
8 \\
9 \\
10 \\
11 \\
12 \\
13 \\
14 \\
15 \\
16 \\
17 \\
18 \\
19 \\
20 \\
21 \\
\text { Mean } \\
\text { (1SD) }\end{array}$ & $\begin{array}{l}60 \\
77 \\
70 \\
68 \\
72 \\
56 \\
53 \\
53 \\
83 \\
70 \\
45 \\
53 \\
62 \\
72 \\
71 \\
74 \\
51 \\
63 \\
70 \\
75 \\
75 \\
65(10) \\
\end{array}$ & $\begin{array}{l}\mathbf{M} \\
\mathbf{M} \\
\mathbf{F} \\
\mathbf{F} \\
\mathbf{M} \\
\mathbf{M} \\
\mathbf{F} \\
\mathbf{M} \\
\mathbf{M} \\
\mathbf{F} \\
\mathbf{M} \\
\mathbf{M} \\
\mathbf{F} \\
\mathbf{M} \\
\mathbf{M} \\
\mathbf{M} \\
\mathbf{M} \\
\mathbf{F} \\
\mathbf{M} \\
\mathbf{M} \\
\mathbf{F}\end{array}$ & $\begin{array}{l}6 \mathrm{~h} \\
3 \mathrm{~h} \\
1 \mathrm{~h} \\
5 \mathrm{~h} \\
2 \mathrm{~h} \\
9 \mathrm{~h} \\
3 \mathrm{~h} \\
6 \mathrm{~h} \\
2 \mathrm{~h} \\
4 \mathrm{~h} \\
2 \mathrm{~h} \\
6 \mathrm{~h} \\
5 \mathrm{~h} \\
3 \mathrm{~h} \\
8 \mathrm{~h} \\
3 \mathrm{~h} \\
2 \mathrm{~h} \\
3 \mathrm{~h} \\
5 \mathrm{~h} \\
4 \mathrm{~h} \\
9 \mathrm{~h} \\
4(2) \mathrm{h}\end{array}$ & $\begin{array}{c}60 \\
36 \\
96 \\
24 \\
48 \\
72 \\
72 \\
96 \\
24 \\
60 \\
60 \\
24 \\
108 \\
36 \\
96 \\
24 \\
96 \\
0 \\
74 \\
168 \\
0 \\
59(41)\end{array}$ & $\begin{array}{c}1 \mathrm{~h} \\
1 \mathrm{~h} \\
2 \mathrm{~h} \\
3 \mathrm{~h} \\
3 \mathrm{~h} \\
3 \mathrm{~h} \\
7 \mathrm{~h} \\
9 \mathrm{~h} \\
12 \mathrm{~h} \\
16 \mathrm{~h} \\
19 \mathrm{~h} \\
25 \mathrm{~h} \\
2 \text { days } \\
2 \text { days } \\
3 \text { days } \\
3 \text { days } \\
4 \text { days } \\
4 \text { days } \\
5 \text { days } \\
6 \text { days } \\
7 \text { days } \\
1.8(2 \cdot 3) \\
\text { days }\end{array}$ & $\begin{array}{l}\text { Rupture } \\
\text { Shock } \\
\text { Shock } \\
\text { Shock } \\
\text { Shock } \\
\text { Shock } \\
\text { Shock } \\
\text { Shock } \\
\text { Shock } \\
\text { Shock } \\
\text { Shock } \\
\text { Shock } \\
\text { Rupture } \\
\text { Rupture } \\
\text { Rupture } \\
\text { Shock } \\
\text { Shock } \\
\text { Rupture } \\
\text { Shock } \\
\text { Shock } \\
\text { Shock }\end{array}$ \\
\hline
\end{tabular}

AMI, acute myocardial infarction; UK, urokinase; Rupture, cardiac rupture; Shock, cardiogenic shock.

( $300 \mathrm{mg} /$ day) and a low dose of heparin (5000 units every 8-12 hours).

All the angiograms were reviewed by three experienced cardiologists, according to the system recommended by the American Heart Association. ${ }^{15}$ To evaluate the stenosis the arteriogram was magnified $(\times 5)$ and the luminal diameter was measured with callipers. On the basis of the angiographic appearance we classified all the segments with stenosis of $75 \%-99 \%$ by diameter as stenoses with smooth narrowing, irregular borders, or filling defects.

The hearts were fixed in $10 \%$ formalin. The epicardial coronary arteries were decalcified (if necessary) and cut transversely and serially from the ostium to the periphery every $2-3 \mathrm{~mm}$ and examined directly. The coronary arteries were divided into 15 segments according to the reporting system recommended by the American Heart Association. ${ }^{15}$ The point with the most severe stenosis in each of the 15 segments of the coronary arteries was embedded in paraffin. Then we used a microtome to obtain sections of $4 \mu \mathrm{m}$. We used branches of the coronary arteries as landmarks to ensure that specific angiographic lesions were examined histologically. The stenosis was examined again after the preparation was stained with elastic van Gieson. In the segments with stenosis of $\geqslant 75 \%$ the sections with the most severe stenosis and the segments $3 \mathrm{~mm}$ on either side of them were sectioned serially every $100 \mu \mathrm{m}$.
All sections were stained with haematoxylin eosin and elastic van Gieson. They were examined for intraluminal thrombus, haemorrhage in the atheromatous plaque, or rupture of the atheromatous plaque.

So that we could compare the results of cineangiography and histology we ensured that the same branches of the major coronary arteries were examined both by coronary angiography and histological examination.

\section{STATISTICAL ANALYSIS}

Data were analysed by $\chi^{2}$ test with Yates' correction and by one way analysis of variance to test for multiple comparisons. A difference of $p<0.05$ was regarded as significant.

\section{Results}

We classified the 21 infarct related segments as six with complete occlusion despite coronary thrombolysis and 15 without complete occlusion (table 2). Five of the six occluded segments contained intraluminal thrombus but only one of the segments without occlusion did ( $p<0.05$ ) (figure). Rupture of the atheromatous plaque and haemorrhage in the atheromatous plaque were equally common in both groups.

Thirty eight segments from the study group of 21 patients showed high grade $(>75 \%)$ stenosis. This total included 15 stenoses that were displayed by angiography after thrombolysis. Fifteen of the stenoses showed angiographically irregular narrowing, two intraluminal filling defects, and 21 smooth narrowing (table 3, figure). Thrombus, rupture of the atheromatous plaque, and haemorrhage in the atheromatous plaque and infarct related arteries were seen in $0,80,80$, and $67 \%$ in the segments with angiographically irregular narrowing and in $0,10,5$, and $14 \%$ in the segments with angiographically smooth narrowing $(p<0.05)$. The two segments with angiographically detected filling defects were infarct related arteries with rupture and haemorrhage in the atheromatous plaque; thrombus was seen in one.

Table 2 Histological findings and stenosis shown by coronary cineangiography (CAG) in the infarct related segments

\begin{tabular}{lcccc}
\hline CAG results & $\begin{array}{l}\text { No of } \\
\text { patients }\end{array}$ & Thrombus & $\begin{array}{l}\text { Rupture of } \\
\text { atheroma }\end{array}$ & $\begin{array}{l}\text { Haemorrhage } \\
\text { in atheroma }\end{array}$ \\
\hline $\begin{array}{c}\text { Persistent } \\
\text { occlusion }\end{array}$ & 6 & $5(84 \%)^{\star}$ & $5(84 \%)$ & $5(84 \%)$ \\
$\begin{array}{c}\text { Patent (but } \\
<75 \% \text { stenosis) }\end{array}$ & 15 & $1(7 \%)^{\star}$ & $13(87 \%)$ & $12(80 \%)$ \\
\hline
\end{tabular}

$\star p<0.05$. 

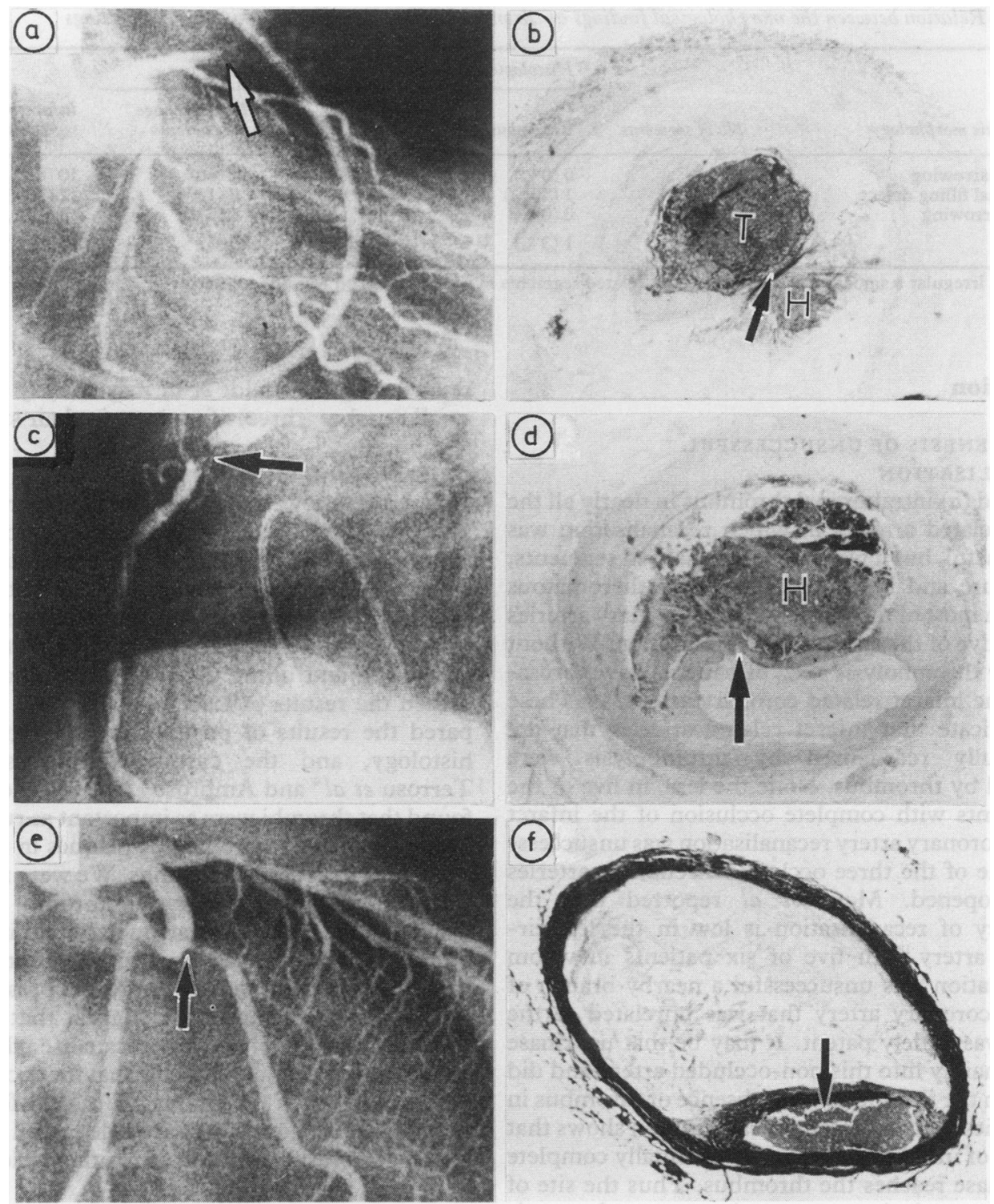

Figure Histology of the coronary artery and angiographic findings. (a) left coronary angiogram of patient 13. (b) Histological section of segment 6 of the patient. Segment 6 showed complete occlusion (arrow) in coronary cineangiography despite intracoronary thrombolysis. Histology showed an intraluminal thrombus $(T)$ and haemorrhage $(H)$ and rupture (arrow) of the atheromatous plaque. (c) Right coronary angiogram of patient 9. (d) Histological section of segment 1 of patient 9 . In coronary cineangiography, segment 1 showed recanalisation with irregular narrowing after thrombolysis. Segment 1 showed haemorrhage $(H)$ and rupture (arrow) of the atheromatous plaque and no thrombus. (e) Left coronary angiogram of patient 18. (f) Histological section of segment 11 of patient 18. Coronary cineangiography showed smooth narrowing with $90 \%$ stenosis (arrow). Histological examination found neither intraluminal thrombus nor rupture or haemorrhage of the atheromatous plaque in the segment. The arrow indicates the lumen. 
Table 3 Relation between the morphological findings at coronary cineangiography and histological findings

\begin{tabular}{|c|c|c|c|c|c|}
\hline \multirow[b]{2}{*}{ Angiographic morphology } & \multirow[b]{2}{*}{ No of segments } & \multicolumn{3}{|c|}{ Histological findings } & \multirow[b]{2}{*}{$\begin{array}{l}\text { Infarct related } \\
\text { segments }\end{array}$} \\
\hline & & Thrombus & $\begin{array}{l}\text { Rupture of } \\
\text { atheroma }\end{array}$ & $\begin{array}{l}\text { Haemorrhage } \\
\text { in atheroma }\end{array}$ & \\
\hline $\begin{array}{l}\text { Irregular narrowing } \\
\text { Intraluminal filling defect } \\
\text { Smooth narrowing }\end{array}$ & $\begin{array}{r}15 \\
2 \\
21\end{array}$ & $\begin{array}{l}0(0 \%) \\
1(50 \%) \\
0(0 \%)\end{array}$ & $\begin{array}{l}12(80 \%)^{\star} \\
2(100 \%) \\
2(10 \%)^{\star}\end{array}$ & $\begin{array}{l}12(80 \%)^{\star} \\
2(100 \%) \\
1(5 \%)^{\star}\end{array}$ & $\begin{array}{l}10(67 \%)^{\star} \\
2(100 \%) \\
3(14 \%)^{\star}\end{array}$ \\
\hline Mean & 38 & $1(3 \%)$ & $16(42 \%)$ & $15(39 \%)$ & $15 \dagger(40 \%) \dagger$ \\
\hline
\end{tabular}

${ }^{*} \mathrm{p}<0.05$, irregular $v$ smooth narrowing. †Infarct related segments in which occlusion was not complete.

\section{Discussion}

\section{PATHOGENESIS OF UNSUCCESSFUL}

RECANALISATION

We found (a) intraluminal thrombus in nearly all the infarct related arteries in which recanalisation was unsuccessful, but it was rare in recanalised segments; (b) rupture and haemorrhage of the atheromatous plaque in most of the infarct related coronary arteries irrespective of the success of recanalisation. Without coronary thrombolysis $90 \%$ of patients have thrombus in the infarct related coronary artery. ${ }^{1617}$ These data indicate that infarct related arteries that are successfully recanalised by thrombolysis were occluded by thrombus. None the less, in five of the six patients with complete occlusion of the infarct related coronary artery recanalisation was unsuccessful. None of the three occluded circumflex arteries were reopened. Merx et al reported that the frequency of recanalisation is low in the left circumflex artery. ${ }^{18}$ In five of six patients in whom recanalisation was unsuccessful a nearby branch of the left coronary artery that was unrelated to the infarct was widely patent. It may be that urokinase flowed mainly into this non-occluded artery and did not reach the thrombus. The absence of thrombus in the arteries with successful recanalisation shows that the lysis of intraluminal thrombi is usually complete if urokinase reaches the thrombus. Thus the site of thrombus may be important to the success of recanalisation.

In the recanalised arteries of patients treated with selective intracoronary thrombolysis, the residual stenosis was caused by atheromas with rupture and haemorrhage. However, Mattfeldt et al reported that they did not see rupture and haemorrhage of the atheromatous plaque in three patients with successful recanalisation. ${ }^{13}$ But rupture and haemorrhage of atheromatous plaques are found in about $90 \%$ of patients with acute myocardial infarction not treated with intracoronary thrombolysis ${ }^{1617} 1920$ and recanalisation is successful in about $80 \%$ of patients treated with intracoronary thrombolysis. ${ }^{18}$ So the results reported by Mattfeldt et al may merely reflect the small number (three) of patients in their study.

\section{CINEANGIOGRAPHIC RESULTS}

Our results showed that the irregular narrowing and $O$ filling defects on cineangiograms coincided with rupture and haemorrhage of atheromatous plaques, whereas a smooth narrowing showed that there was no rupture or haemorrhage. We also found that the infarct related arteries showed frequent irregular narrowing and filling defects. These findings confirmed the results of Levin and Fallon, ${ }^{10}$ who compared the results of postmortem angiography and histology, and the cineangiography studies of Terrosu et $a l^{9}$ and Ambrose et al. ${ }^{112}$ These groups found that thrombi were as important as rupture and haemorrhage of atheromatous plaques in the pathogenesis of irregular narrowings. We were not able to establish the relation between thrombi found by histology and irregular narrowing or filling defects found by cineangiography because after coronary thrombolysis there were few thrombi present.

The results of our study suggest that failure of coronary thrombolysis to recanalise the infarct related artery does not indicate that the occlusion was not caused by a thrombus. We also found that findings at angiography accorded well with the histological features of coronary atherosclerosis.

We thank S Tomita and $M$ Jinnai for their technical assistance and $M s M$ Ohara for reading the manu- $N$ script.

This study was supported in part by a research grant from the Ministry of Education, Science, and Culture, Japan.

\section{References}

1 Rentrop P, Blanke H, Karsch KR, Kreuzer H. Initial experience with transluminal recanalisation of the recently occluded infarct-related coronary artery in acute myocardial infarction-comparison with conventionally treated patients. Clin Cardiol 1979;2 92-105. 
2 Ganz W, Buchbinder N, Marcus $\mathrm{H}$, et al. Intracoronary thrombolysis in evolving myocardial infarction. $\mathbf{A m}$ Heart J 1981;101:4-13.

3 Markis JE, Malagold M, Parker JA, et al. Myocardial salvage after intracoronary thrombolysis with streptokinase in acute myocardial infarction. $N$ Engl $J$ Med 1981;305:777-82.

4 Ferguson DW, White CW, Schwartz JL, et al. Influence of baseline ejection fraction and success of thrombolysis on mortality and ventricular function after acute myocardial infarction. Am J Cardiol 1984; 54:705-11.

5 Hartzler GO, Rutherford BD, McConahay DR, et al. Percutaneous transluminal coronary angioplasty with and without thrombolytic therapy for treatment of acute myocardial infarction. Am Heart J 1983; 106:965-73.

6 Dodge HT, Sheehan FN, Mathey DG, Brown BG, Kennedy JW. Usefulness of coronary artery bypass graft surgery or percutaneous transluminal angioplasty after thrombolytic therapy. Circulation 1985;72(suppl V):39-45.

7 Prida XE, Holland JP, Feldman RL, et al. Percutaneous transluminal coronary angioplasty in evolving acute myocardial infarction. $A m J$ Cardiol 1986;57: 1069-74.

8 Fujiwara H, Onodera T, Tanaka M, et al. A clinicopathologic study of patients with hemorrhagic infarction treated with selective coronary thrombolysis with urokinase. Circulation 1986;73:749-57.

9 Terrosu P, Vibba GV, Contini GM, Franceschino V. Angiographic features of the coronary arteries during intracoronary thrombolysis. $B r$ Heart $J$ 1984;52: $154-63$.

10 Levin DC, Fallon JT. Significance of the angiographic morphology of localised coronary stenoses: histopathologic correlations. Circulation 1982;66:316-20.

11 Ambrose JA, Winters SL, Stern A, et al. Angiographic morphology and the pathogenesis of unstable angina pectoris. J Am Coll Cardiol 1985;5:609-16.

12 Ambrose JA, Winters SL, Arora RR, et al. Coronary angiographic morphology in myocardial infarction: a link between the pathogenesis of unstable angina and myocardial infarction. J Am Coll Cardiol 1985;6: 1233-8.

13 Mattfeldt T, Schwarz F, Schuler G, Hoffman M, Kubler $W$. Necropsy evaluation in seven patients with evolving acute myocardial infarction treated with thrombolytic therapy. Am J Cardiol 1984; 54:530-4.

14 Mathey D, Schofer J, Kuck K-H, Beil U, Kloppel G. Transmural, hemorrhagic myocardial infarction after intracoronary streptokinase: clinical, angiographic, and necropsy findings. Br Heart $J$ 1982;48:546-51.

15 Austen WG, Edwards JE, Frye RL, et al. A reporting system on patients evaluated for coronary artery disease. Circulation 1975;51:7-40.

16 Ridolfi RL, Hutchins GM. The relationship between coronary artery lesions and myocardial infarcts: ulceration of atherosclerotic plaques precipitating coronary thrombosis. Am Heart J 1977;93:468-86.

17 Horie T, Sekiguchi M, Hirosawa K. Coronary thrombosis in pathogenesis of acute myocardial infarction: histopathological study of coronary arteries in 108 necropsied cases using serial section. Br Heart $J$ 1978;40:153-61.

18 Merx W, Dorr R, Rentrop P, et al. Evaluation of the effectiveness of intracoronary streptokinase infusion in acute myocardial infarction: postprocedure management and hospital course in 204 patients. Am Heart J 1981;102:1181-7.

19 Chapman I. Morphogenesis of occluding artery thrombosis. Arch Pathol 1965;80:256-61.

20 Friedman M, Van Den Bovenkamp GJ. The pathogenesis of a coronary thrombus. Am J Pathol 1966;48: 19-31. 